\title{
The Hypersensitive Induced Reaction and Leucine-Rich Repeat Proteins Regulate Plant Cell Death Associated with Disease and Plant Immunity
}

\author{
Hyong Woo Choi, Young Jin Kim, and Byung Kook Hwang \\ Laboratory of Molecular Plant Pathology, School of Life Sciences and Biotechnology, Korea University, Anam-dong, \\ Sungbuk-ku, Seoul 136-713, Republic of Korea
}

Submitted 2 February 2010. Accepted 28 June 2010.

\begin{abstract}
Pathogen-induced programmed cell death (PCD) is intimately linked with disease resistance and susceptibility. However, the molecular components regulating PCD, including hypersensitive and susceptible cell death, are largely unknown in plants. In this study, we show that pathogeninduced Capsicum annuum hypersensitive induced reaction 1 (CaHIRI) and leucine-rich repeat 1 (CaLRRI) function as distinct plant PCD regulators in pepper plants during Xanthomonas campestris pv. vesicatoria infection. Confocal microscopy and protein gel blot analyses revealed that CaLRR1 and CaHIR1 localize to the extracellular matrix and plasma membrane (PM), respectively. Bimolecular fluorescent complementation and coimmunoprecipitation assays showed that the extracellular CaLRR1 specifically binds to the PM-located CaHIR1 in pepper leaves. Overexpression of CaHIRI triggered pathogen-independent cell death in pepper and Nicotiana benthamiana plants but not in yeast cells. Virus-induced gene silencing (VIGS) of CaLRRI and CaHIRI distinctly strengthened and compromised hypersensitive and susceptible cell death in pepper plants, respectively. Endogenous salicylic acid levels and pathogenesis-related gene transcripts were elevated in CaHIRI-silenced plants. VIGS of NbLRRI and NbHIRI, the $N$. benthamiana orthologs of CaLRR1 and CaHIR1, regulated Bax- and avrPto-/Pto-induced PCD. Taken together, these results suggest that leucine-rich repeat and hypersensitive induced reaction proteins may act as cell-death regulators associated with plant immunity and disease.
\end{abstract}

Programmed cell death (PCD), a highly regulated and sophisticated cellular mechanism, has been implicated as a common feature in incompatible and compatible plant-microbe interactions (Greenberg and Yao 2004; Williams and Dickman 2008). In incompatible interactions, the hypersensitive response (HR), a type of plant PCD, occurs immediately after the contact of a

Nucleotide sequence data of CaHIR1 and CaLRR1 from this article can be found in the GenBank data libraries under accession number AY529867 and AY237117, respectively.

Corresponding author: B. K. Hwang; E-mail: bkhwang@korea.ac.kr; Telephone: +82-32903061; Fax: +82-9211715.

* The $\boldsymbol{e}$-Xtra logo stands for "electronic extra" and indicates that five supplementary figures and two supplementary tables are published online and that Figures 1, 2, 3, 5, and 6 appear in color online. single bacterium with a plant cell, resulting in the activation of local and systemic acquired resistance (SAR) to protect plants from attacks by a wide range of pathogens (Choi et al. 2007; del Pozo et al. 2004; Durrant and Dong 2001; Jones and Dangl 2006; Park 2005). Significant progress in understanding the molecular mechanisms underlying the HR has been achieved through the cloning and characterization of plant resistance genes involved in the recognition of pathogen avirulence factors (Jones and Dangl 2006). Subsequent analyses to dissect genetic pathways mediating the HR have led to the isolation of lesion-mimic mutants, such as accelerated cell death (acd), lesion-stimulating disease-resistance response ( $l s d)$, and $d n d$ (defense, no death) mutant plants (Balagué et al. 2003; Clough et al. 2000; Mühlenbock et al. 2008; Yao and Greenberg 2006; Yu et al. 1998). In compatible plant-microbe interactions, however, susceptible cell death occurs relatively late during the course of infection. There is an increasing body of evidence to indicate that host-controlled PCD is also intimately linked with the onset of susceptible cell death and symptom development in plants (Greenberg and Yao 2004; Hwang et al. 2008; Navarre and Wolpert 1999; Yao et al. 2002). In Nicotiana benthamiana plants, virus-induced gene silencing (VIGS) of a mitogen-activated protein kinase kinase kinase gene $(M A P K K K \alpha)$, a positive regulator of cell death, compromises disease-associated cell death accompanied by reduced growth of Pseudomonas syringae (del Pozo et al. 2004). This suggests that hostcontrolled cell death during a compatible interaction may be triggered by virulent $P$. syringae. However, the molecular components regulating susceptible cell death are poorly understood in plants.

The CaHIRl (Capsicum annuum hypersensitive induced reaction 1) gene was identified in a pepper cDNA library in an attempt to characterize host cellular factors that specifically interact with CaLRRI (Capsicum annuum leucine-rich repeat 1) (Jung and Hwang 2007; Jung et al. 2004). Ectopic expression of CaHIRl in Arabidopsis plants regulates the cell-death response to various pathogens as well as to osmotic stress, accompanied by changes in the induction of some defense-related genes and proteins (Jung et al. 2008). In an earlier study, tobacco NG1 cDNA was isolated during a functional search for genes whose products elicited the HR in tobacco (Karrer et al. 1998). NG1 expression induces the formation of disease symptoms and expression of the PR-2 protein. The three maize hypersensitive induced reaction (HIR) genes (Zm-hirl, Zm-hir2, and Zm-hir3) were identified based on their amino acid homology to the tobacco NG1 sequence (Nadimpalli et al. 2000). Among them, 
the Zm-hir3 gene is strongly induced in the maize lesion mimic mutant Les9, suggesting a possible role of maize HIR genes for HR cell-death execution. Nadimpalli and associates (2000) showed that maize HIR proteins along with prohibitins and stomatins form a PID (proliferation, ion, and death) protein superfamily. Interestingly, these PID proteins share common features in their SPFH (stomatins, prohibitins, flotillins, HflK/C) domains. Prohibitin proteins are involved in mitochondrial biogenesis and in the protection of plants against stress and senescence (Ahn et al. 2006), and stomatins are integral membrane proteins of red blood cells that function as negative regulators of cation permeability (Nadimpalli et al. 2000). The presence of the SPFH domain in HIR proteins and their structural similarity to prohibitins and stomatins suggest that they may function as ion channel regulators. However, the molecular function of HIR proteins in cell-death execution is unknown.

Leucine-rich repeat (LRR) proteins have diverse functions and cellular locations in plants and animals (Federici et al. 2006; Kobe and Kajava 2001; Padmanabhan et al. 2009; Shanmugam 2005). In animal systems, LRR proteins have been shown to regulate gene expression and apoptosis signaling (Kobe and Kajava 2001). In plant systems, LRR proteins also appear to be involved in protein-protein interactions and signal transduction pathways that regulate PCD (Padmanabhan et al. 2009). The presence of LRR domains in the majority of disease-resistance proteins and receptor-like kinases (RLK) underscores the pivotal roles of LRR domains in gene-for-gene resistance and intracellular signaling events. Genetic and molecular genetic analyses in Arabidopsis ecotypes Col-0 and Po- 1 revealed that the LRR domain of RPS2 determines specific interactions of RPS2 with other host factors during the RPS2-mediated disease-resistance response (Banerjee et al. 2001). However, the role of small LRR proteins, which lack the cytoplasmic kinase domain, is largely unknown in plant defense. Recently, the small LRR tobacco protein NtLRP1 was demonstrated to negatively regulate PCD (Jacques et al. 2006). Agrobacteriummediated transient expression of endoplasmic reticulumlocated NtLRPI suppressed PCD induced by the fungal elicitin $\beta$-megaspermin. These findings suggest that small LRR proteins along with R proteins and RLK are involved in the regulation of plant PCD through a specific interaction with pathogen-derived ligands or host proteins.

In a previous gain-of-function study, overexpression of the CaHIRI gene in Arabidopsis was found to result in the spontaneous cell-death phenotype, which was accompanied by increased $\mathrm{K}^{+}$efflux and salicylic acid (SA) pathway-dependent $P R$ gene induction (Jung and Hwang 2007). Moreover, co-overexpression of both CaLRRI and CaHIRl in transgenic Arabidopsis plants compromised CaHIRl-mediated $P R$ gene expression and the cell-death phenotype. Thus, we hypothesized that the CaLRR1 protein specifically interacts with the CaHIR1 protein and suppresses cell death induced by CaHIR1. In this study, we used the Tobacco rattle virus (TRV)-based VIGS technique to further define the functional roles of CaLRR1 and CaHIR1 in disease resistance and cell death of pepper plants. It is time-consuming and very difficult to generate transgenic pepper plants. The VIGS technique not only provided a fast and effective means to generate loss-of-function phenotypes but also allowed us to identify the functional roles of $C a L R R I$ and $C a H I R I$ for cell death and defense responses of pepper plants. CaLRRI- and CaHIRI-silenced pepper plants exhibited enhanced and reduced cell-death phenotypes during Xanthomonas campestris pv. vesicatoria infection, respectively. However, the enhanced celldeath response of CaLRRI-silenced pepper plants did not significantly promote disease resistance. In contrast, silencing of CaHIRI significantly compromised hypersensitive and susceptible cell deaths, which were accompanied by elevated SA levels and $P R$-gene expression. We discuss LRR- and HIR-mediated cell death in comparison to the cell death and HR-based innate immune response of $N$. benthamiana plants following Agrobacterium-mediated transient expression of Bax, AvrPto, and AvrPto/Pto.

\section{RESULTS}

\section{Extracellular CaLRR1 interacts with membrane-associated CaHIR1 to form membrane microdomains.}

Computational analyses of the predicted protein sequences revealed that CaLRR1 possesses four LRR domains and that CaHIR1 has an SPFH domain (SMART database) that contains putative transmembrane helices between amino-acid residues 30 and 49 (TMpred database) (Fig. 1A). To investigate the subcellular localization and distribution of CaLRR1 and CaHIR1, we used a biolistic transformation system in onion epidermal cells. As shown in Figure 1B, soluble-modified green fluorescent protein (smGFP)-tagged CaLRR1 and CaHIR1 proteins were localized in small patches at the plasma membrane (PM). This distinct punctate localization along the PM is characteristic of various membrane microdomain proteins (Latif et al. 2003; Solis et al. 2007). Using different constructs, we next identified the CaHIR1 domains involved in punctate localization in the PM. Interestingly, smGFP-tagged $\triangle \mathrm{C}$ consisting of the SPFH domain but not smGFP-tagged $\triangle$ SPFH exhibited punctate localization that is similar to that of CaHIR1. Furthermore, the smGFP-tagged transmembrane domain of CaHIR1, which contains the 20 amino-acid residues of putative transmembrane helices, was localized to the PM, without punctate characteristics. Intriguingly, the PM of onion epidermal cells expressing the CaHIRI:smGFP construct but not the CaLRRl:smGFP construct was detached from the cell wall, leaving a visible gap, which is a characteristic of apoptotic-like PCD (Reape and McCabe 2008).

To determine whether CaLRR1 and CaHIR1 are extracellular or membrane-associated proteins, total and extracellular proteins were extracted from pepper leaves $6 \mathrm{~h}$ after avirulent $X$. campestris pv. vesicatoria infection. Total, soluble, microsomal, and extracellular proteins were subjected to sodium dodecyl sulfate-polyacrylamide gel electrophoresis (SDS-PAGE) and were immunoblotted using anti-CaLRR1 and anti-CaHIR1 polyclonal antibodies (Fig. 1C). The CaLRR1 protein was enriched in the extracellular protein extract, suggesting that it localizes to the extracellular matrix. However, the CaHIR1 protein was detected in the separated microsomal fraction, indicating that it is a membrane-associated protein.

CaHIR1 was initially identified as a molecular partner of CaLRR1 by yeast two-hybrid screening (Jung and Hwang 2007). We used the bimolecular fluorescence complementation (BiFC) technique to examine heterodimerization of CaLRR1 with CaHIR1 in pepper leaves (Fig. 1D) (Walter et al. 2004). Most of the fluorescence signals induced by heterodimerization of CaLRR1 with CaHIR1 were located in the punctate site of the PM and the peripheral region of pepper epidermal cells. However, we could not detect fluorescence signals in pepper epidermal cells infiltrated with single plasmids or empty vectors (Supplementary Fig. 1). Coimmunoprecipitation experiment also revealed the specific interaction of CaHIR1 with CaLRR1 (Fig. 1E). Taken together, these findings suggest that extracellular CaLRR1 specifically interacts with PM-associated CaHIR1 to form membrane microdomains, which may function as platforms for compartmentalizing various cellular processes, such as membrane transport, protein sorting, calcium homeostasis, and signal transduction (Browman et al. 2007). 


\section{Agroexpression of $C a L R R 1$ and $C a H I R 1$ alters defense responses of pepper plants.}

Overexpression of CaLRR1 suppresses CaHIRl-induced cell death in Arabidopsis and tobacco (Nicotiana tabacum cv. Xanthi) plants (Jung and Hwang 2007). Because transformation is very difficult in pepper plants, an Agrobacterium-mediated transient expression (agroexpression) system was used to gain insight into the in vivo function of CaLRRI and CaHIRI in pepper plants. Transient expression of $C a H I R 1$ in pepper leaves strongly induced cell death 4 days after agroinfiltration; however, coexpression of CaLRRI and CaHIRl significantly suppressed cell death in these tissues (Fig. 2A and B). Measurements of electrolyte leakage supported significantly attenuated or strengthened cell death in CaLRRI- or CaHIRI-expressing pepper leaf tissues, respectively (Fig. 2C). These findings suggest that overexpression of CaLRRl suppresses CaHIRl-induced cell death in pepper plants, as observed in Arabidopsis and tobacco plants (Jung and Hwang 2007).
UV illumination of pepper leaves 4 days after agroinfiltration revealed that transient activation of CaLRRI and CaHIRI strongly induced and caused accumulation of defense-related fluorescent phenolic compounds (blue), compared with the empty-vector control, which induced yellowish chlorosis (Fig. 2A). Transient CaLRRI expression strongly induced $\mathrm{H}_{2} \mathrm{O}_{2}$ accumulation (Supplementary Fig. 2) and common defenserelated genes, including CaHIRl, CaBPRl, CaPOA1, CaPR10, and $C a D E F 1$; however, transient CaHIRI expression did not induce these defense-related genes (Fig. 2E and F). Interestingly, agroexpression of both CaLRRI and CaHIRl in pepper leaves strongly induced most of the analyzed defense-related genes, with the exception of CaPOA1. Aniline blue staining of pepper leaves revealed attenuated and strengthened callose deposition in pepper leaves after agroexpression of CaLRRI and CaHIRl, respectively, compared with the empty-vector control leaves (Fig. 2B and D). Callose or callose synthase have been demonstrated to negatively regulate the SA pathway
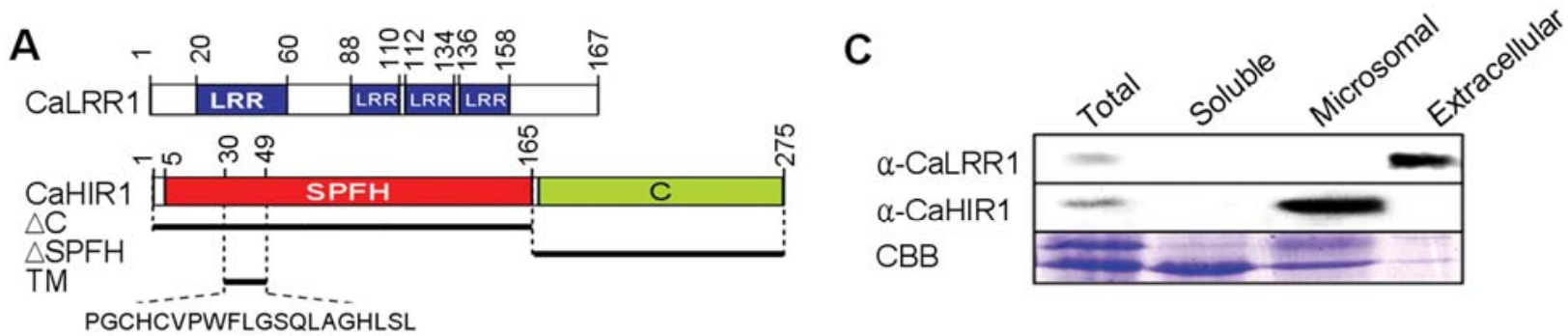

B

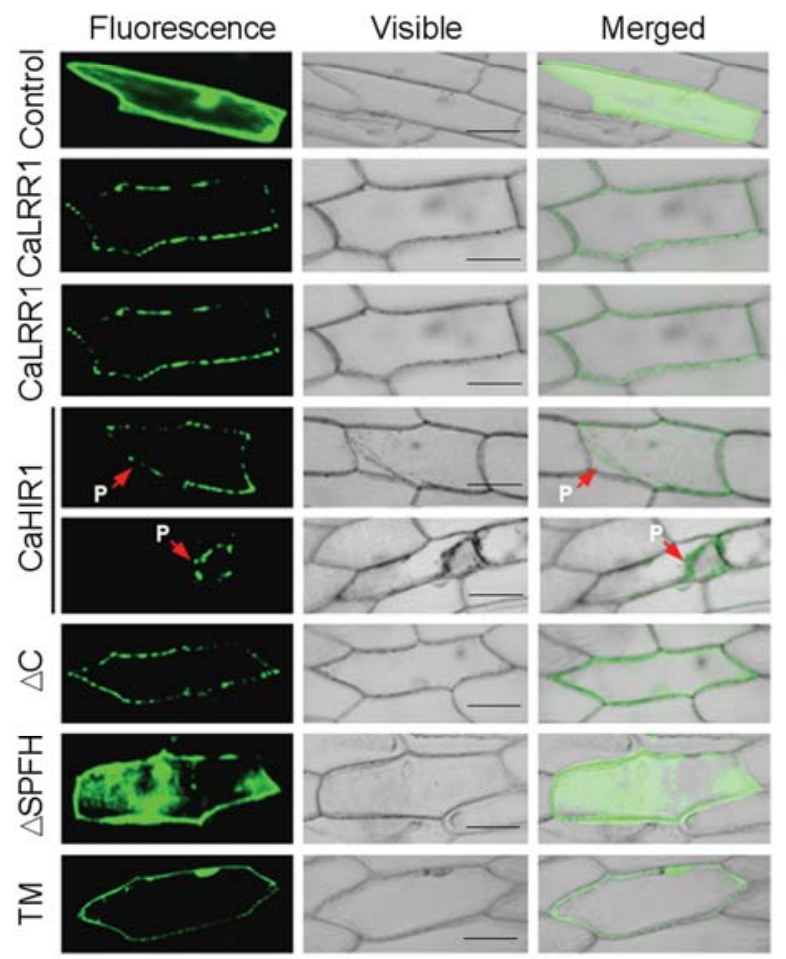

D
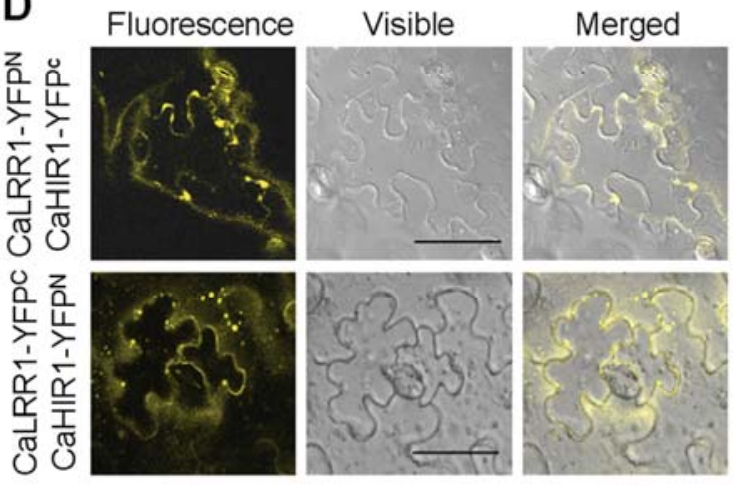

$\mathrm{E}$

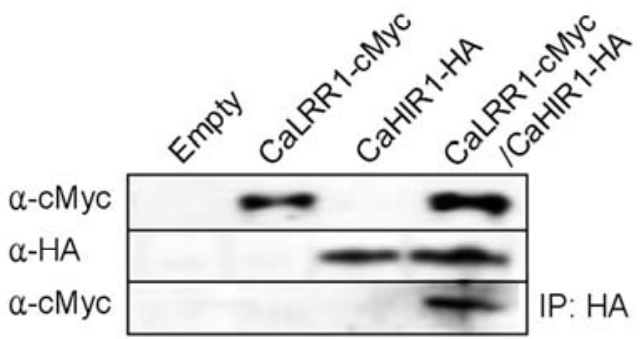

Fig. 1. Structure, subcellular localization, and bimolecular fluorescence complementation (BiFC) visualization of CaLRR1 and CaHIR1. A, Domain structures of the CaLRR1 and CaHIR1 proteins and constructs. Numbers refer to encoded amino acids. LRR = leucine-rich repeat domain, SPFH = stomatin, prohibitin, flotillins, HflK/C domain, TM = transmembrane domain, and $\mathrm{C}=$ uncharacterized C-terminal region. B, Punctate localization of soluble-modified green fluorescent protein (smGFP)-tagged CaLRR1 and CaHIR1 proteins in the plasma membrane (PM) of onion (Allium cepa L.) epidermal cells. $\mathrm{P}=\mathrm{PM}$ in plasmolyzed cells and Control = 35S:smGFP. The SPFH domain of CaHIR1 is sufficient for the punctate localization of CaHIR1 in the PM. Bars = 100 $\mu$ m. C, Immunological detection of the subcellular localization of CaLRR1 and CaHIR1 in pepper leaves infected with Xanthomonas campestris pv. vesicatoria. CaLRR1 and CaHIR1 are extracellular and membrane-bound proteins, respectively. Membranes were probed with polyclonal antibodies raised against CaLRR1 or CaHIR1 in rabbits. Protein loading is shown by Coomassie brilliant blue (CBB) staining. D, BiFC visualization of CaLRR1 and CaHIR1 heterodimerization in pepper leaves. Confocal images of yellow fluorescent protein (YFP) signals (Fluorescence) induced by interaction of CaLRR1 with CaHIR1 and bright field images (Visible) of pepper epidermal leaf cells. Bars $=100 \mu \mathrm{m}$. E, Coimmunoprecipitation of CaLRR1 and CaHIR1 in pepper leaves. CaLRR1-cMyc and CaHIRI-hemagglutinin (HA) transgenes were expressed in pepper leaves by agroexpression. Total proteins were extracted from leaves and were subjected to immunoprecipitation (IP) with anti-HA antibody-conjugated beads. Total and immunoprecipitated proteins were immunoblotted with the indicated antibodies. 
in the Arabidopsis powdery mildew resistant 4 (pmr4) mutant, which does not deposit callose (Nishimura et al. 2003). Thus, strengthened callose deposition by transient expression of CaHIRI may reflect the suppression of the SA-dependant defense signaling pathway in pepper plants.

SA accumulation, SA-dependent cell death, and $P R$ gene expression have been proposed to be intimately correlated with disease resistance in higher plants (Vlot et al. 2009). We analyzed whether endogenous SA is involved in the CaLRRI- and CaHIRl-mediated defense responses, including cell death and $P R$ gene expression (Fig. 2G). SA accumulation was significantly enhanced and suppressed in transiently CaLRRI- and
CaHIRl-expressing pepper leaves, respectively, compared with the Agrobacterium empty vector-expressing leaves. Furthermore, coexpression of CaLRRI with $C a H I R I$ compromised CaLRRl-induced SA accumulation in pepper leaves. These results suggest that CaLRRI and CaHIRI positively and negatively regulate $\mathrm{SA}$ accumulation in pepper plants, respectively.

\section{VIGS of CaLRRI and CaHIRI}

alters the defense responses of pepper plants.

The TRV-based VIGS technique has been used as an efficient reverse genetics approach to define the functions of defenserelated genes involved in the disease resistance of pepper
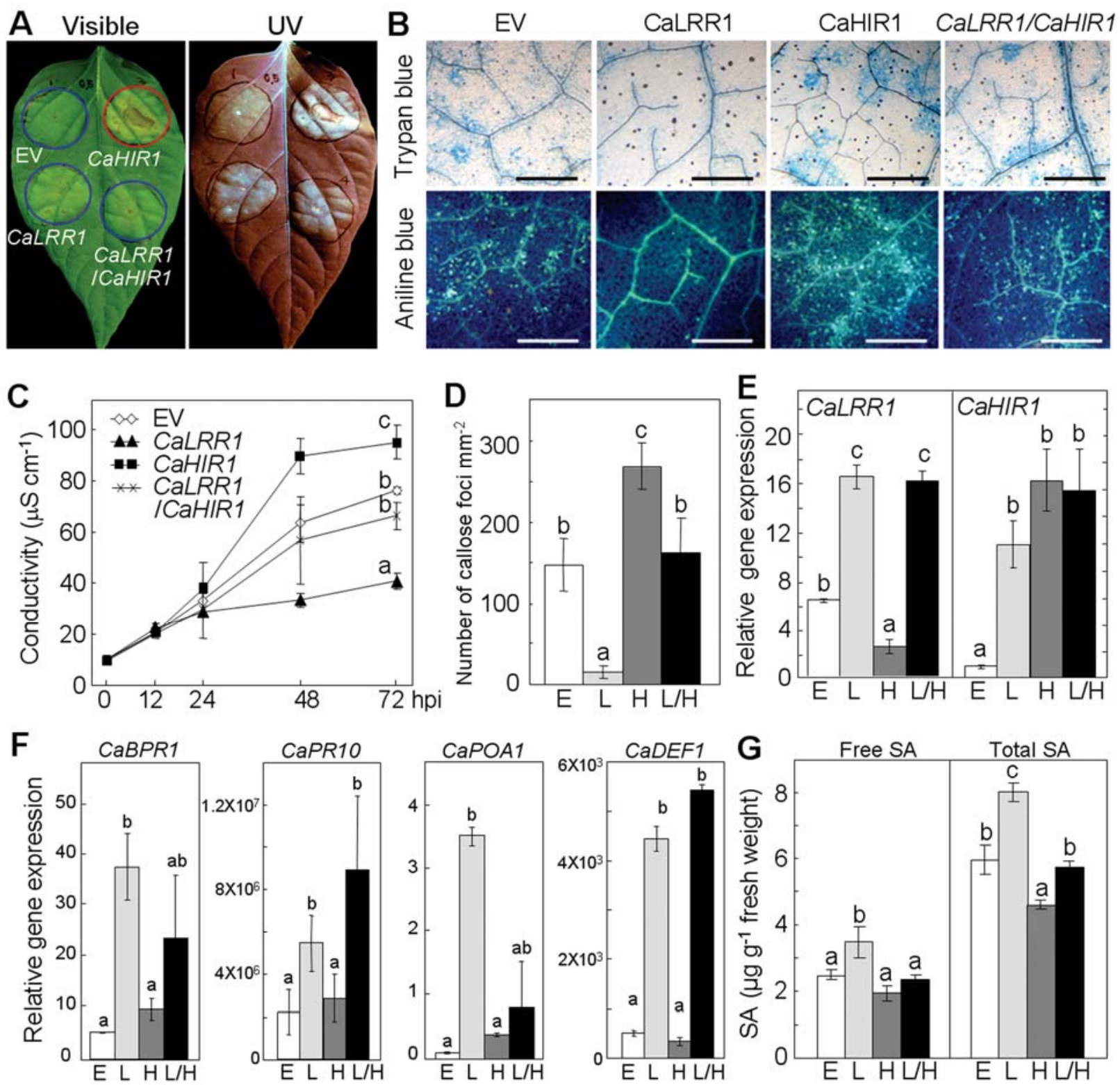

Fig. 2. Effects of agroexpression of CaLRRI and CaHIRl on cell death and defense responses of pepper leaves. A, Cell-death response caused in the pepper leaf by transient expression of CaHIRl (left panel). Chlorophyll autofluorescence (red), chlorosis (yellow), and accumulation of defense-related phenolic compounds (blue) were visualized by UV illumination (right panel) 4 days after inoculation. The blue and red circles indicate the absence and presence of cell death, respectively. EV = empty vector. B, Trypan blue and aniline blue staining of pepper leaves $48 \mathrm{~h}$ after agroexpression with the indicated transgenes. Bars $=500 \mu \mathrm{m}$. $\mathbf{C}$, Ion leakage from leaf disks of pepper plants $0,12,24,48$, and $78 \mathrm{~h}$ after inoculation with Agrobacterium tumefaciens carrying the indicated transgenes. D, Number of callose foci in pepper leaves $48 \mathrm{~h}$ after agroexpression of CaLRR1 and CaHIR1. Callose deposition was quantified from more than ten leaf regions. E and F, Real-time reverse transcription-polymerase chain reaction analysis of expression of the CaLRR1, CaHIR1, CaBPR1 (pepper basic PR1), CaPR10 (pepper PR10), CaPOA1 (pepper ascorbate peroxidase), and CaDEF1 (pepper defensin) genes in pepper leaves $24 \mathrm{~h}$ after agroexpression of the indicated transgenes. Expression of the pepper 18s rRNA gene served as a control. G, Salicylic acid accumulation in pepper leaves $24 \mathrm{~h}$ after inoculation with A. tumefaciens carrying the indicated transgenes. The data in $\mathbf{C}, \mathbf{D}, \mathbf{E}, \mathbf{F}$, and $\mathbf{G}$ are the mean \pm standard deviation from four independent experiments. Statistically significant differences between means were determined by employing Fisher's least significant difference test. Different letters indicate significant differences at $P=0.05$. E $=$ empty vector; $\mathrm{L}=35 \mathrm{~S}: \mathrm{CaLRR} 1 ; \mathrm{H}=35 \mathrm{~S}: \mathrm{CaHIR} 1$; and $\mathrm{L} / \mathrm{H}=35 \mathrm{~S}: \mathrm{CaLRR} 1$ and 35S:CaHIRI. 
plants (Choi et al. 2007, 2008; Lee et al. 2008; Liu et al. 2002). During infection with the avirulent $X$. campestris pv. vesicatoria Bv5-4a, VIGS of CaLRR1 and CaHIR1 remarkably compromised the accumulation of their transcripts and proteins
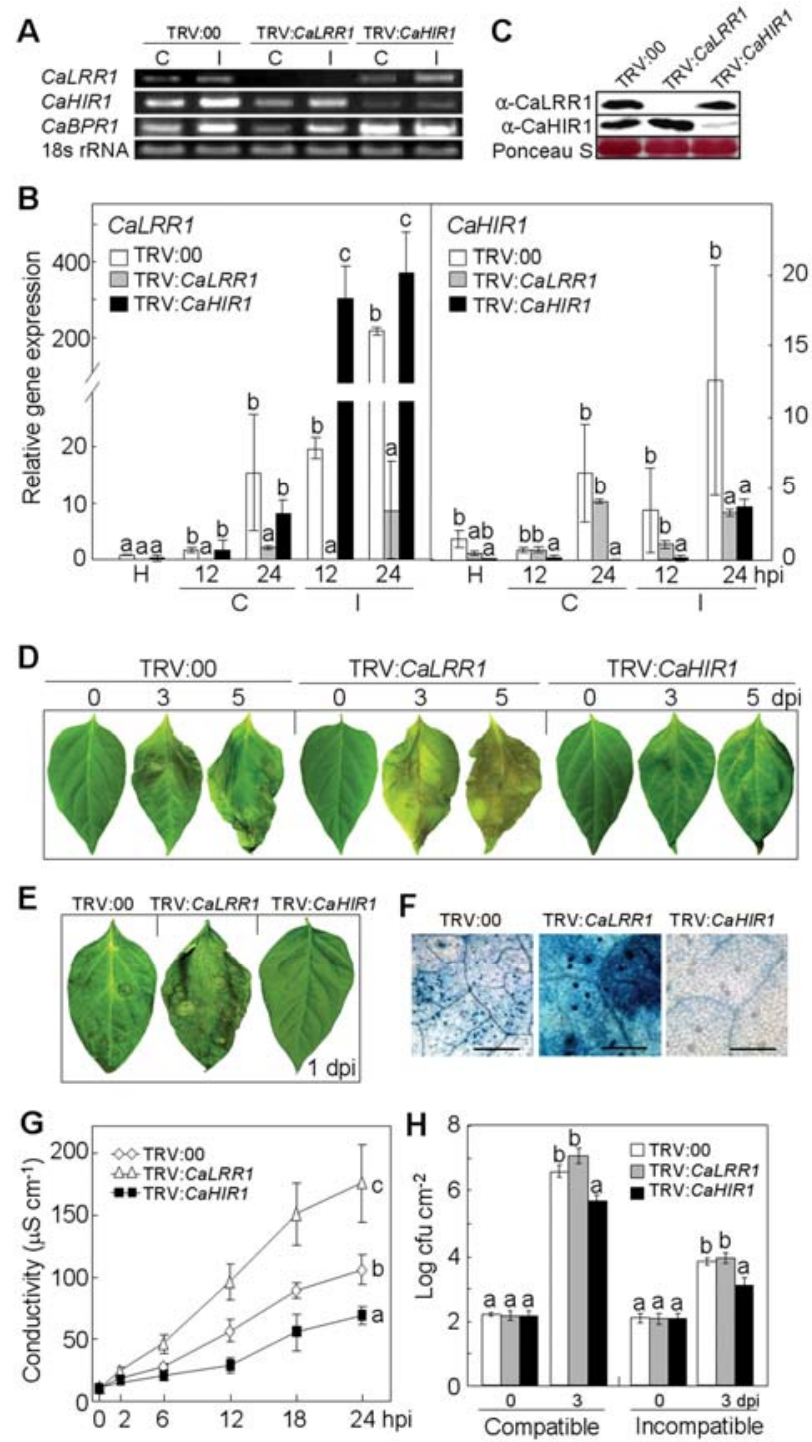

Fig. 3. Effects of virus-induced gene silencing of CaLRR1 or CaHIR1 on the defense responses of pepper plants. A, Reverse transcription-polymerase chain reaction (RT-PCR) analyses of expression of the CaLRR1, CaHIRl, and CaBPRl genes in gene-silenced pepper leaves $6 \mathrm{~h}$ after inoculation (hpi) with the virulent $(\mathrm{C}=$ compatible) Ds1 and avirulent $(\mathrm{I}=$ incompatible) Bv5-4a strains of Xanthomonas campestris pv. vesicatoria $\left(10^{5} \mathrm{CFU} \mathrm{ml^{-1 }}\right)$. B, Real-time RT-PCR analyses of expression of the CaLRR1 and CaHIR1 genes in gene-silenced pepper leaves 12 and $24 \mathrm{hpi}$

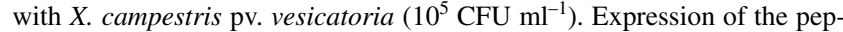
per 18 s rRNA gene served as a control. $\mathrm{H}=$ uninoculated healthy leaves. C, Immunological detection of CaLRR1 and CaHIR1 in gene-silenced pepper leaves 6 hpi with the $X$. campestris pv. vesicatoria avirulent strain

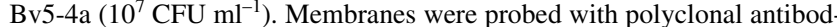
ies raised against CaLRR1 or CaHIR1 in rabbits. Protein loading is shown by Ponceau S staining. D, Disease symptoms on gene-silenced pepper leaves 0,3 , and 5 days after inoculation (dpi) with the virulent strain of $X$. campestris pv. vesicatoria $\left(10^{5} \mathrm{CFU} \mathrm{m \textrm {m } ^ { - 1 }}\right)$. E, Hypersensitive response phenotype, $\mathbf{F}$, trypan blue staining, and $\mathbf{G}$, Ion leakage measurement of gene-silenced pepper leaves inoculated with avirulent $X$. campestris pv. vesicatoria $\left(10^{7} \mathrm{CFU} \mathrm{ml} \mathrm{m}^{-1}\right)$. $\mathbf{H}$, Bacterial growth in gene-silenced pepper leaves 0 and 3 dpi with virulent and avirulent $X$. campestris pv. vesicatoria. The data in $\mathbf{B}, \mathbf{G}$, and $\mathbf{H}$ are the means \pm standard deviation from four independent experiments. Statistically significant differences between means were determined by employing Fisher's least significant difference test. Different letters indicate significant differences at $P=0.05$. compared with the effect of the unsilenced empty vector in control leaves (TRV:00); however, CaHIRl transcripts and proteins remained at a slightly visible level in CaHIRl-silenced pepper leaves (Fig. 3A, B, and C). This result suggests that silencing was effective for $C a L R R I$ and $C a H I R I$. Interestingly, VIGS of CaLRRI significantly suppressed CaHIRl expression in both healthy and avirulent $X$. campestris pv. vesicatoria-inoculated pepper leaves. These findings suggest that CaHIRI expression may be involved in the CaLRRI-dependent signaling pathway. In contrast, VIGS of CaHIRI significantly enhanced CaLRRI expression in avirulent $X$. campestris pv. vesicatoria-inoculated pepper leaves, suggesting that CaHIRl may negatively regulate $\mathrm{C} a L R R I$ expression.

The biological functions of CaLRRI and CaHIR1 during infection were evaluated in gene-silenced pepper leaves inoculated with the virulent strain Ds1 or the avirulent strain Bv5-4a of $X$. campestris pv. vesicatoria. CaLRRI-silenced leaves exhibited enhanced susceptibility-induced chlorosis and cell death upon virulent and avirulent $X$. campestris pv. vesicatoria infection, respectively (Fig. 3D and E). However, silencing of CaLRRI did not significantly enhance bacterial growth in leaves (Fig. 3H). In contrast, silencing of CaHIRl compromised susceptibility-induced cell death during $X$. campestris pv. vesicatoria infection. Typical chlorotic susceptible disease symptoms were not observed in CaHIRl-silenced leaves 5 days after virulent $X$. campestris pv. vesicatoria inoculation (Fig. 3D; Supplementary Fig. 3). Trypan blue staining and ion leakage measurement revealed extensively strengthened and attenuated cell death in CaLRRI- and CaHIRI-silenced leaves, respectively, compared with empty-vector control leaves after inoculation with avirulent $X$. campestris pv. vesicatoria (Fig. $3 \mathrm{~F}$ and $\mathrm{G}) . \mathrm{CaHIR} 1$-silenced leaves exhibited significantly enhanced resistance to both virulent and avirulent $X$. campestris pv. vesicatoria, as observed by bacterial growth (Fig. $3 \mathrm{H}$ ). Together, these findings suggest that CaHIRl-mediated cell death is dependent upon disease susceptibility (Clough et al. 2000; Greenberg et al. 2000).

To determine whether silencing of CaLRRI or CaHIRI affects the expression of genes involved in disease resistance, we further analyzed the transcript levels of several defenserelated pepper genes by quantitative reverse transcriptionpolymerase chain reaction (RT-PCR) (Fig. 4A). Silencing of CaHIRl remarkably induced CaBPRI, CaPOA1, CaPR10, and $C a D E F 1$ in pepper leaves, compared with expression in empty-vector control leaves during infection with virulent and avirulent $X$. campestris pv. vesicatoria. Furthermore, a high level of CaPOAl transcripts was expressed in CaHIRl-silenced leaves uninoculated with $X$. campestris pv. vesicatoria. In contrast, silencing of CaLRRI distinctly compromised expression of CaHIRI, CaPOA1, CaPR10, and CaDEF1 in leaves infected by avirulent $X$. campestris pv. vesicatoria. We next determined SA levels in CaLRRI- and CaHIRI-silenced leaves 1 and 3 days after inoculation with virulent and avirulent $X$. campestris pv. vesicatoria (Fig. 4B). Silencing of CaHIRl but not of CaLRRI significantly enhanced SA levels in pepper leaves during $X$. campestris pv. vesicatoria infection, especially in the incompatible interactions. This indicates that CaHIRImediated cell death does not induce SA accumulation in pepper leaves. It is also noteworthy that a high level of SA in pepper leaves is required for the CaLRRI-mediated resistance response.

\section{Silencing of $N b L R R 1$ and $N b H I R 1$ alters PCD in $N$. benthamiana leaves.}

Ectopic or transient overexpression of CaHIRl induced the cell-death response in Arabidopsis, tobacco ( $N$. tabacum cv. Xanthi), and pepper plants (Fig. 2A) (Jung and Hwang 2007). 
Thus, we hypothesized that CaHIRl may act as a trigger of plant cell-death execution. Transient expression of CaHIR1, but not CaLRRI, in $N$. benthamiana induced the cell-death phenotype 8 days after agroinfiltration (Fig. 5A and B). To determine whether CaHIRl-mediated cell death affects HRbased immunity in $N$. benthamiana, we used the avrPto/Ptomediated PCD system. The signaling components necessary for Pto-mediated PCD are conserved in N. benthamiana (Sessa et al. 2000). As expected, Agrobacterium-transient expression of avrPto and avrPto/Pto induced chlorosis and HR-like cell death, respectively (Fig. 5C). Surprisingly, transient coexpression of CaLRRI or CaHIRl with avrPto compromised or strengthened, respectively, avrPto-mediated chlorosis.

The nucleotide sequences of CaLRRI and CaHIRI share 62 and $87 \%$ identities with putative $N$. benthamiana LRRI (NbLRR1; accession number CK291392) and N. benthamiana HIRl (NbHIR1; accession number CK292032), respectively (Supplementary Fig. 4). To determine whether the NbLRRl and $N b H I R I$ genes are involved in cell-death regulation, we silenced these genes in $N$. benthamiana plants using TRV2:CaLRR1 and TRV2:CaHIRI constructs. The efficiency of VIGS of NbLRRI and NbHIRI was examined by RT-PCR analysis (Fig. 5D). The silenced leaves lacked endogenous NbLRRI and NbHIRl transcripts, indicating that silencing was effective for NbLRRI and NbHIRl.

$N$. benthamiana leaves silenced for $N b L R R I$ and $N b H I R I$ genes were infiltrated with Agrobacterium strains carrying the following transgenes expressed by the $C a M V 35 S$ promoter: the tomato $R$ gene Pto, the Pseudomonas syringae avirulence gene avrPto, and the mouse proapoptotic effector gene Bax (Fig. 5E, F, and G) (Lacomme and Santa Cruz 1999). In empty-vector control leaves (TRV:00), PCD occurred in areas expressing Bax and avrPto/Pto. The avrPto/Pto-induced PCD phenotypes were much stronger than the Bax-induced phenotypes. As expected, transient expression of avrPto alone triggered the chlorosis phenotype in the empty-vector control leaves, whereas Pto expression had no effect in control or silenced leaves. Baxmediated PCD was more pronounced in NbLRRI-silenced leaves compared with empty-vector control leaves. More importantly, Agrobacterium-mediated transient expression of Bax, avrPto/Pto, or avrPto induced distinct cell-death phenotypes in NbLRRI-silenced leaves. In contrast, silencing of NbHIRI compromised Bax- and avrPto/Pto-mediated PCD in N. ben- thamiana leaves. Measurements of electrolyte leakage supported significantly strengthened or attenuated cell death in NbLRRIor $N b H I R l$-silenced leaf tissues, respectively, following Agrobacterium-mediated transient expression of avrPto, avrPto/Pto, and Bax (Fig. 5G). Taken together, these findings support the notion that LRR1 (CaLRRI or NbLRRI) and HIR1 (CaHIRI or $N b H I R l)$ may act as negative and positive regulators of cell death in plants, respectively.

\section{HIR protein is a plant-specific modulator of cellular defense and cell death.}

To investigate whether CaHIR 1 acts as a general component of eukaryotic cell-death execution, we expressed the gene in yeast cells. However, we failed to detect CaHIR1-induced cell death in yeast cells (Supplementary Fig. 5). Our phylogenetic analyses of 56 members of the SPFH superfamily revealed that 16 HIR proteins from diverse plant species constitute one family that is distinguished from other SPFH proteins from diverse phyla (Fig. 6).

\section{DISCUSSION}

\section{CaHIR1 acts as a positive regulator}

of PCD associated with plant immunity and disease.

Transient expression of CaHIR1 triggered cell death in pepper and $N$. benthamiana plants. In contrast, VIGS of CaHIRl suppressed not only disease progression but also hypersensitive cell death in response to virulent and avirulent $X$. campestris pv. vesicatoria infection, respectively. In addition, silencing of NbHIRl, a N. benthamiana ortholog of CaHIRl, compromised Bax- and avrPto/Pto-induced PCD in N. benthamiana plants. Collectively, these findings support the notion that CaHIR1 acts as a positive regulator of PCD associated with plant immunity and disease susceptibility. In terms of the primary and secondary predicted protein structures and hydropathy profiles, plant HIR proteins are proposed to belong to a PID (proliferation, ion, and death) protein superfamily that also includes prohibitins and stomatins (Nadimpalli et al. 2000). Members of these gene families exhibit diverse expression patterns under stressful conditions, suggesting pivotal roles in plant defense responses (Ahn et al. 2006; Nadimpalli et al. 2000; Rostoks et al. 2003). More recently, proteomics analysis of PM proteins revealed a differential accumulation of OsHIR1 in
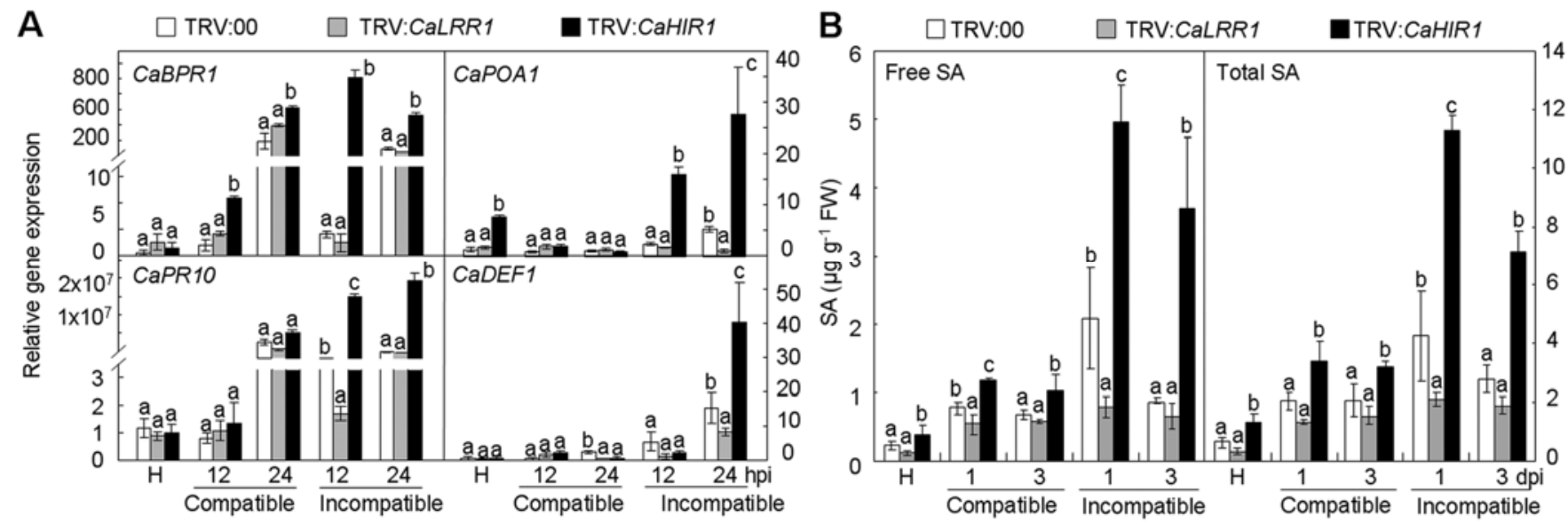

Fig. 4. Effects of virus-induced gene silencing of CaLRRI or CaHIRI on pepper defense-related gene expression and salicylic acid (SA) accumulation. A, Real-time reverse transcription-polymerase chain reaction analyses of expression of pepper defense-related genes in gene-silenced pepper leaves 12 and $24 \mathrm{~h}$ after inoculation (hai) with the virulent (compatible) Ds1 and avirulent (incompatible) Bv5-4a strains of Xanthomonas campestris pv. vesicatoria (10 ${ }^{5}$ CFU $\mathrm{ml}^{-1}$ ). Expression of the pepper 18s rRNA gene served as a control. B, SA accumulation in CaLRR1-and CaHIR1-silenced pepper leaves 1 and 3 days after

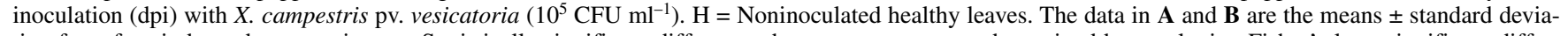
tion from four independent experiments. Statistically significant differences between means were determined by employing Fisher's least significant difference test. Different letters indicate significant differences at $P=0.05$. 
rice suspension cells during infection with Xanthomonas oryzae pv. oryzae (Chen et al. 2007). These findings, together with our agroexpression and VIGS studies, provide in vivo evidence for a functional role of HIR proteins in the execution of plant PCD.

\section{Membrane-bound CaHIR1 interacts with extracellular CaLRR1.}

The CaLRRI and CaHIRl genes encode LRR and SPFH domain-containing proteins, respectively, for which biological functions have not been fully defined. Confocal microscopy and protein gel-blot analyses revealed that CaLRR1 and CaHIR1 are extracellular and PM-associated proteins, respectively. BiFC and coimmunoprecipitation assays showed that extracellular CaLRR1 is capable of forming a complex with the PM-associated, SPFH domain-containing CaHIR1 protein in pepper plants. Strikingly, both smGFP-tagged CaLRR1 and CaHIR1 proteins exhibited punctate localization along the PM of onion epidermal cells. This pattern may be due to the presence of the SPFH domain within the protein, which is essential for triggering cell death by forming a microdomain. The punctate localization of both CaLRR1 and CaHIR1 in the PM of onion cells indicates that these proteins may physically bind to each other on the PM of pepper cells. These findings are well supported by recent observations that the SPFH domain-containing microdomain protein flotillin/reggie in vertebrates is punctately localized along the PM (Langhorst et al. 2007, 2008). Punctate localization of smGFP-tagged CaLRR1 in onion epidermal cells also raises the possibility that onion cells may contain functional CaHIR1 homologues that can bind CaLRR1 to form a microdomain in the membrane (Zhou et al. 2009). These microdomain proteins may be involved in various cellular signaling pathways, such as neural regeneration, cell proliferation, clathrin- and caveolin-independent endocytosis, and T-cell activation (Babuke and Tikkanen 2007; Browman et al. 2007; Rivera-Milla et al. 2006). Recently, direct interaction between OsLRR1 and OsHIR1, which are rice orthologs of CaLRR1 and CaHIR1, was demonstrated by yeast two-hybrid and in vitro pull-down assays (Zhou et al. 2009). The LRR1 and HIR1 orthologs was shown to be highly conserved among different plant species, including Arabidopsis plants. Our findings combined with these ortholog data support strong evidence that the defense-related LRR1 and HIR1 microdomain may be conserved in plant species.

\section{Negative feedback regulation of $C a L R R I$ \\ by $C a H I R 1$ determines endogenous $\mathrm{SA}$ levels in pepper.}

Our interesting finding concerning CaHIRl silencing in pepper leaves is that bacterial growth is significantly reduced in silenced pepper leaves infected by virulent $X$. campestris $\mathrm{pv}$. vesicatoria as well as avirulent $X$. campestris pv. vesicatoria, despite the absence of the HR. This raises the possibility that the expression of CaHIRl suppresses the defense responses of pepper plants to promote $X$. campestris pv. vesicatoria infection. Real-time RT-PCR analyses revealed that induction of the CaLRRI and CaHIRl genes by X. campestris pv. vesicatoria infection distinctly regulates the downstream SA-dependent defense marker genes CaBPR1, CaPR10, and CaPOA1. The

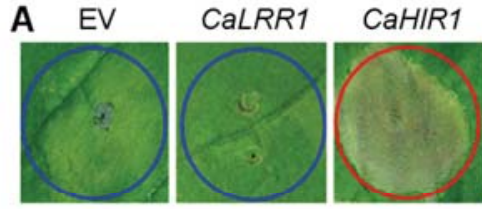

B

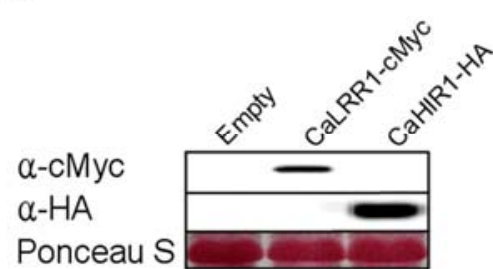

G

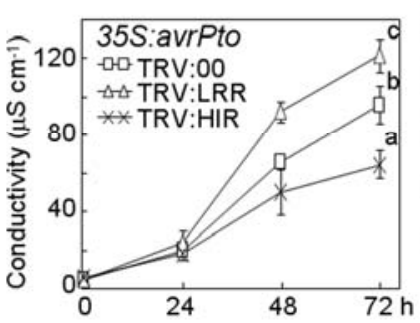

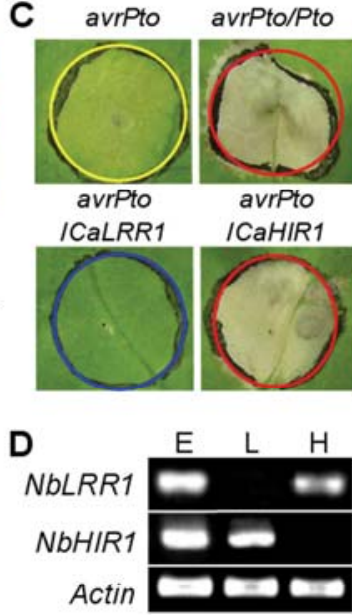

E

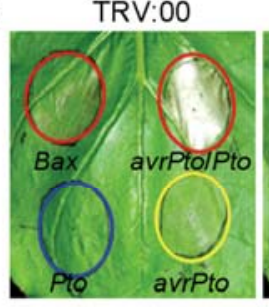

TRV:CaLRR1

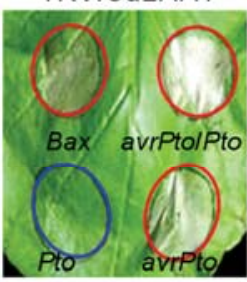

TRV:CaHIR1

$\mathbf{F}$

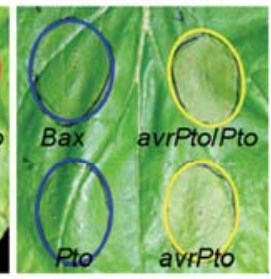

\begin{tabular}{c|ccc}
\hline \multicolumn{4}{l}{ Cell death scores in NbLRR1- or NbHIR1-silenced $N$. benthamiana leaves } \\
$\begin{array}{c}\text { Agro VIGS } \\
\text { expression }\end{array}$ & $\begin{array}{c}\text { TRV:00 } \\
(n=4)\end{array}$ & $\begin{array}{c}\text { TRV:CaLRR1 } \\
(n=9)\end{array}$ & $\begin{array}{c}\text { TRV:CaHIR1 } \\
(n=6)\end{array}$ \\
\hline Bax & $(1 / 3 / 0)$ & $(8 / 1 / 0)$ & $(0 / 2 / 4)$ \\
\hline Pto & $(0 / 0 / 4)$ & $(0 / 0 / 9)$ & $(0 / 0 / 6)$ \\
\hline avnPto & $(0 / 0 / 4)$ & $(7 / 2 / 0)$ & $(0 / 0 / 6)$ \\
\hline avrPto/Pto & $(4 / 0 / 0)$ & $(9 / 0 / 0)$ & $(2 / 2 / 2)$ \\
\hline$(n / n / n)=($ cell death / moderate cell death / no cell death)
\end{tabular}

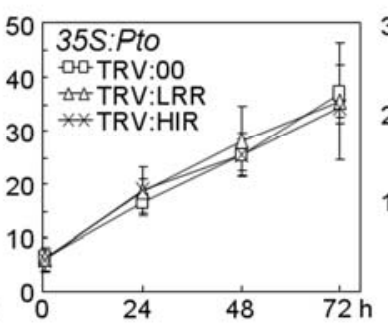

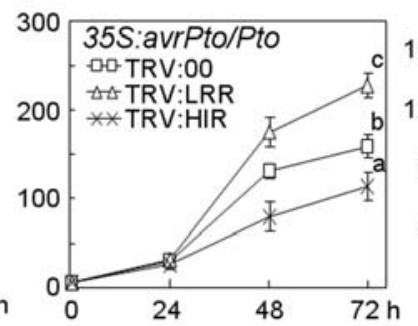

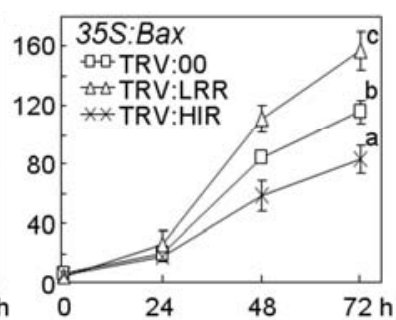

Fig. 5. Effects of virus-induced gene silencing of NbLRRI and NbHIRI on Bax- and Pto/AvrPto-induced cell death and AvrPto-induced chlorosis. A, CaHIR1-induced cell death in leaves. Pictures were taken 8 days after agroexpression. B, Immunological detection of CaLRR1-cMyc and CaHIR1-hemagglutinin proteins, using the indicated antibodies in leaves 2 days after inoculation with Agrobacterium tumefaciens carrying the indicated transgenes. Protein loading is shown by Ponceau S staining. C, Responses of Nicotiana benthamiana leaves to agroexpression of the indicated transgenes. Pictures were taken 4 days after agroexpression. D, Reverse transcription-polymerase chain reaction analyses of the $N b L R R 1$ and $N b H I R 1$ genes in $N b L R R I$ - or $N b H I R l$-silenced leaves. E, Effects of NbLRRI or NbHIRI silencing on Bax- and avrPto/Pto-induced cell death and avrPto-induced chlorosis in leaves. The blue, yellow, and red circles indicate no cell death, chlorosis, and cell death, respectively. F, Cell-death scores for agroexpression of Bax, avrPto, Pto, and avrPto/Pto in NbLRRI- or NbHIRl-silenced leaves. G, Quantification of electrolyte leakage from disks of $N b L R R I$ - or $N b H I R I$-silenced leaves 0 , 24, 48, and 72 h after inoculation with $A$. tumefaciens carrying the indicated transgenes. Statistically significant differences between means were determined by employing Fisher's least significant difference test. Different letters indicate significant differences at $P=0.05$. 
altered expression of these SA-dependent genes in pepper leaves may lead to subsequent changes in the levels of endogenous SA, an important signaling molecule for defense response in plants (Durrant and Dong 2001). Importantly, transient expression of CaLRR1 was very effective in enhancing endogenous SA levels in pepper plants, suggesting that CaLRR1 positively regulates SA-dependent defense signaling in pepper plants. However, we detected only slight decreases in SA levels of CaLRRI-silenced plants infected by $X$. campestris pv. vesicatoria. In contrast, transient expression or silencing of CaHIRI drastically reduced or enhanced SA levels in pepper leaves, respectively, indicating a negative role for CaHIR1 in SA accumulation. Taken together, our data suggest that CaLRR1 and CaHIR1 manipulate the endogenous SA-dependent signal-

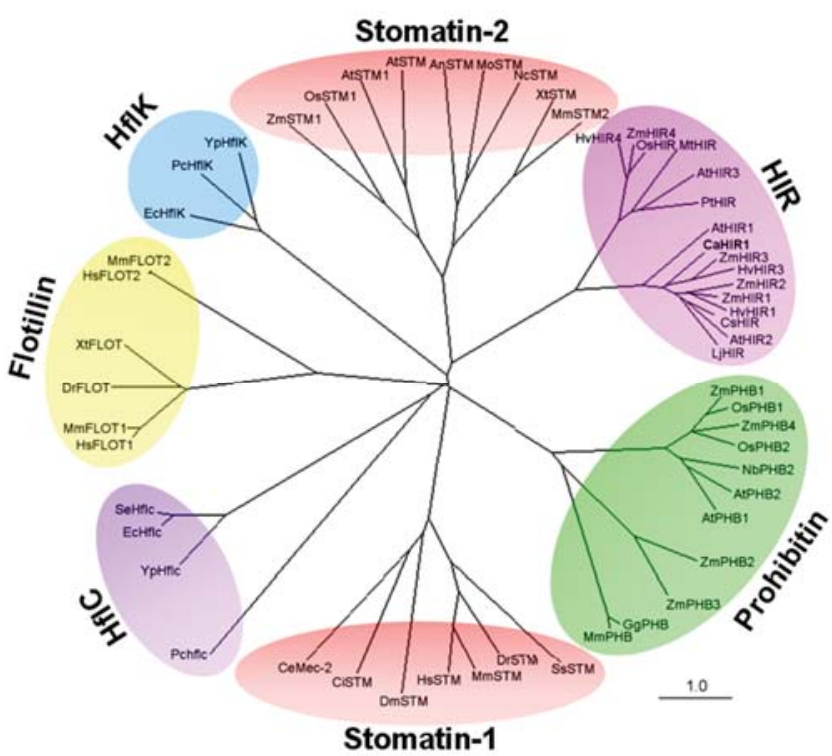

Fig. 6. An unrooted neighbor-joining dendrogram depicting the relationship among 56 representatives of the SPFH (stomatin, prohibitin, flotillins, HflK/C) superfamily and hypersensitive-induced reaction (HIR) proteins. Plant HIR proteins are clearly partitioned by families within the SPFH protein superfamily. The scale value of 0.1 represents 0.1 amino-acid substitutions per site. ing pathway to positively and negatively regulate plant cell death and defense responses, respectively.

A key role of SA is proposed to be the induction of $P R$ gene expression and disease resistance that is frequently associated with HR cell death in plants (Vlot et al. 2009). It is interesting to note complex roles of SA in regulation of cell death. In Arabidopsis lesion-mimic mutants, micro-cell death phenotypes were correlated with spatial and temporal patterns of SA accumulation (Mühlenbock et al. 2008; Yao and Greenberg 2006). However, some of lesion-mimic mutants, such as defense no death 1 (dndl), HR-like lesion mimic 1 (hlml/dnd2), and hypersensitive response-like lesions 1 ( hrll) mutants retain characteristics of gene-for-gene resistance, such as strong SA accumulation and the ability to limit pathogen growth, without the HR (Clough et al. 2000; Balagué et al. 2003; Devadas and Raina 2002; Yu et al. 1998). This raises the possibility that SA accumulation occurs as a result of cell death and the cell death is not influenced by SA levels. Furthermore, constitutively elevated endogenous SA levels in uninfected $d n d 1$, hlml/dnd2, and $\mathrm{hrll}$ mutants support an important role of SA in negative feedback regulation of HR-associated cell death (Balagué et al. 2003; Devadas and Raina 2002; Yu et al. 1998). Consistent with this hypothesis, pretreatment with SA and benzothiadiazole significantly suppressed HR against avirulent pathogen infection in wild-type Arabidopsis plants but not in $n p r l$ and $n a h G$ plants (Devadas and Raina 2002; Vlot et al. 2009). Interestingly, endogenous SA levels were constitutively elevated in $H I R I$-silenced plants. These findings support the notion that the preexisting SA-induced SAR of $H I R l$-silenced plants may serve as one form of negative feedback loop to regulate HRassociated cell death, as observed in $d n d l$, hlml/dnd2, and hrll mutants (Devadas and Raina 2002). Furthermore, transcript levels of SA-inducible $P O A 1$, encoding an important reactive oxygen species (ROS)-detoxifying enzyme (Do et al. 2003), also significantly increased in HIRl-silenced pepper plants noninoculated or inoculated with avirulent $X$. campestris pv. vesicatoria. Therefore, the enhanced ROS-scavenging capacity of $H I R I$-silenced plants may attenuate ROS-triggered cell-death signals during the incompatible interaction.

Real-time RT-PCR analyses revealed that CaLRRI upregulated endogenous $C a H I R I$ expression, whereas $C a H I R I$ downregulated endogenous CaLRRl expression at the transcription

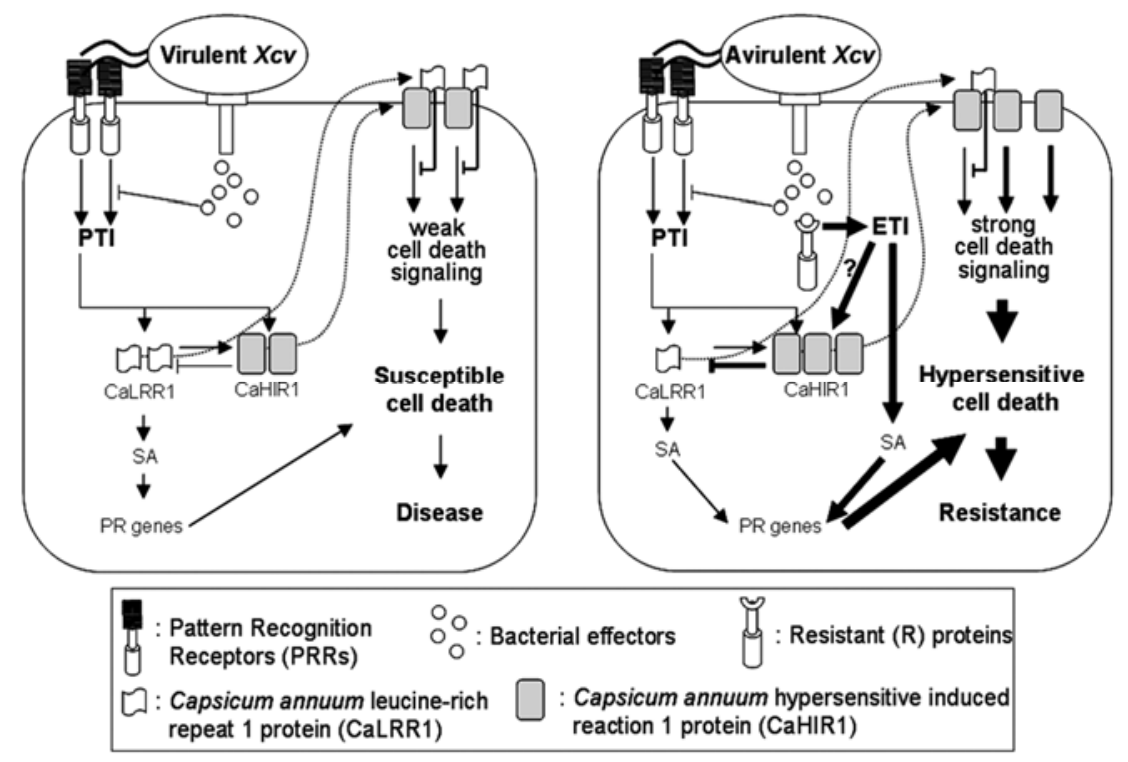

Fig. 7. Proposed model for CaLRR1- and CaHIR1-mediated defense responses and cell death during the compatible and incompatible interactions of Xanthomonas campestris pv. vesicatoria with pepper plants. ETI = effector-triggered immunity and PTI = pathogen-associated molecular pattern-triggered immunity. 
level. These findings raise the possibility that CaLRRI expression is regulated in a negative feedback manner by the induction of CaHIRI. Expression of CaLRRI enhances basal defense through the SA-dependent signaling pathway, simultaneously leading to the induced expression of CaHIR1. Expression of CaHIRl may negatively regulate SA-dependent defense signaling by suppressing CaLRRl expression to evade uncontrolled or excessive activation of defense responses.

\section{Proposed model for the regulation of cell death and defense responses by CaLRR1 and CaHIR1.}

Combining the data we present here, we propose a working model for CaLRR1- and CaHIR1-mediated cell death and defense responses in pepper plants (Fig. 7). $P R$ genes, such as CaBPR 1, CaPOA1, CaPR10, and CaDEF1, are differentially regulated downstream of the SA-dependent pathway, of which the signaling intensity is stronger for effector-triggered immunity (ETI) than for pathogen-associated molecular patterntriggered immunity (PTI) (Jones and Dangl 2006). During the compatible interaction of pepper plants with virulent $X$. campestris pv. vesicatoria, CaLRR1 and CaHIR1 proteins may be induced by PTI. Expression of CaLRRI contributes to the establishment of basal defense through SA-dependent signaling pathways. Induction of CaHIR1 triggers cell-death signals, in which signal intensities are not strong enough to exceed the threshold of the HR in the compatible interaction. Consequently, the signals triggered by CaHIR1 may lead to susceptible cell death during compatible interactions. In contrast, CaHIR1 induction that is strengthened and prolonged by ETI negatively regulates $C a L R R 1$ expression during incompatible interactions of pepper plants with avirulent $X$. campestris pv. vesicatoria. Consequently, the signals triggered by strong induction of CaHIR1 may lead to hypersensitive cell death during the incompatible interaction. However, the absence of catalytic motifs, such as the kinase domain and others, in CaHIR1 proteins makes it difficult to define the role of this protein in regulation of cell death and defense responses. Further studies of the novel CaHIR1-interacting proteins, the molecular mechanisms underlying strengthened and prolonged induction of CaHIR1 by avirulent $X$. campestris pv. vesicatoria, and the antagonistic effects of CaHIR1 on SA-mediated defense signaling are required to gain insights into its role in the regulation of cell death and defense responses.

\section{MATERIALS AND METHODS}

\section{Plant materials and pathogen inoculation.}

Seeds of pepper (Capsicum annuum L. cv. Nockwang) and Nicotiana benthamiana were germinated and grown in pots containing steam-sterilized soil mix (peat moss, perlite, and vermiculite, $5: 3: 2$, vol/vol/vol) and loam soil $(1: 1, \mathrm{vol} / \mathrm{vol})$ at $25^{\circ} \mathrm{C}$ with a $16-\mathrm{h}$ light photoperiod cycle at a light intensity of $70 \mu \mathrm{mol}$ photons $\mathrm{m}^{-2} \mathrm{~s}^{-1}$ (Choi et al. 2007). Pepper plants were inoculated with virulent strain Ds1 and the avirulent strain Bv5-4a of Xanthomonas campestris pv. vesicatoria as previously described (Chung et al. 2007; Kim et al. 2007).

\section{RT-PCR and real-time PCR analyses.}

Total cellular RNA was isolated from plant leaves using TRIzol reagent (Invitrogen, San Diego, CA, U.S.A.) and was treated with RNase-free DNase (Roche, Indianapolis, IN, U.S.A.). First-strand cDNA synthesis and real-time PCR experiments were performed as previously described (Choi et al. 2007). Quantitative RT-PCR data were normalized with the level of the Capsicum annuum 18s rRNA internal transcript control. The gene-specific oligonucleotides used for real-time RT-PCR are listed in Supplementary Table 1.
Coimmunoprecipitation and immunoblotting.

CaLRRI and CaHIRl cDNAs were cloned into the vector pET32a (Novagen, Madison, WI, U.S.A.). Each construct for protein expression was transformed into Escherichia coli BL21 (Invitrogen), and transformants were grown overnight in $5 \mathrm{ml}$ of Luria-Bertani (LB) broth at $37^{\circ} \mathrm{C}$. An aliquot of the culture was added to $50 \mathrm{ml}$ of LB broth and was grown at $37^{\circ} \mathrm{C}$ to an optical density at $600 \mathrm{~nm}\left(\mathrm{OD}_{600}\right)=0.5$. Protein expression was induced with $100 \mu \mathrm{M}$ isopropyl- $\beta$-D-thio-galactoside for $3 \mathrm{~h}$ at $28^{\circ} \mathrm{C}$. The His-tagged CaLRR1 and CaHIR1 proteins were purified using the Ni-NTA purification system kit (Invitrogen). The purified proteins were subjected to SDS-PAGE, were further purified by excising the bands, and were used for the generation of immune sera in rabbits (LabFrontier, Seoul, Korea). Specific binding of immune sera against CaLRR1 or CaHIR1 was confirmed and was used for Western blot analysis.

Total protein extracts were prepared by grinding $1 \mathrm{~g}$ of leaf tissue of pepper or $N$. benthamiana in $2 \mathrm{ml}$ of grinding buffer (20 mM Tris- $\mathrm{HCl}, \mathrm{pH}$ 7.5, $150 \mathrm{mM} \mathrm{NaCl}, 1 \mathrm{mM}$ EDTA, $1 \%$ Triton X-100, 0.1\% SDS, $5 \mathrm{mM}$ dithiothreitol (DTT), and complete protease inhibitor cocktail [Roche, Branchburg, NJ, U.S.A.]), followed by pelleting insoluble debris by centrifugation at $20,000 \times g$ for $15 \mathrm{~min}$ at $4^{\circ} \mathrm{C}$. To separate soluble and microsomal fractions, total proteins were centrifuged for $1 \mathrm{~h}$ at $100,000 \times g$. To extract extracellular proteins, pepper leaf disks were vacuum-infiltrated with extraction buffer $(10 \mathrm{mM}$ phosphate, $0.1 \%$ sodium metabisulphite, $\mathrm{pH}$ 6.8) and were washed three times with sterile water at $4^{\circ} \mathrm{C}$. Discs were dried on filter paper and were centrifuged to collect the extracellular fluid. Protein concentrations were determined by the Bradford protein assay (Bradford 1976). Western blotting was done by a standard method. Equal loading of proteins were ensured by Coomassie blue staining of SDS-PAGE gels or Ponceau S staining of polyvinylidene diflouride (PVDF) membranes.

For immunoprecipitations, $1 \mathrm{~g}$ of leaf tissues of pepper plants infiltrated with Agrobacterium tumefaciens GV3101 carrying each construct were ground in liquid nitrogen with a pestle and mortar and were homogenized in $2 \mathrm{ml}$ of lysis buffer $(50 \mathrm{mM}$ Tris- $\mathrm{HCl}, \mathrm{pH} 7.5,150 \mathrm{mM} \mathrm{NaCl}, 10 \mathrm{mM}$ EDTA, $0.2 \%$ Triton X-100, and complete protease inhibitor cocktail). Insoluble material was pelleted by centrifugation at $20,000 \times g$ for $20 \mathrm{~min}$ at $4^{\circ} \mathrm{C}$. The supernatant $(500 \mu \mathrm{l})$ was combined with $100 \mu \mathrm{l}$ of resuspended anti-hemagglutinin affinity matrix (Roche). After incubation at $4^{\circ} \mathrm{C}$ overnight, the resin was washed four times with $1 \mathrm{ml}$ of lysis buffer and was subjected to centrifugation at $15,000 \times g$ at $4^{\circ} \mathrm{C}$. Electrophoresis sample buffer $(200 \mu \mathrm{l})(20 \mathrm{mM}$ Tris- $\mathrm{HCl}, \mathrm{pH} 7.5,2 \mathrm{mM}$ EDTA, 5\% SDS, $0.02 \%$ bromophenol blue, $20 \%$ glycerol, and $200 \mathrm{mM}$ DTT) was added to the washed pellets, and the mixture was boiled for $5 \mathrm{~min}$ and, then, centrifuged at 15,000 $\times \mathrm{g}$ at $4{ }^{\circ} \mathrm{C}$. Supernatant $(30 \mu \mathrm{l})$ was subjected to SDS-PAGE and transferred to PVDF membrane for immunoblotting using anticMyc antibody (Sigma, St. Louis).

\section{Particle bombardment.}

The coding regions of the CaLRRI and CaHIRl genes were cloned between the CaMV35 promoter and the smGFP region of the binary vector p326GFP to generate $3^{\prime}$ fusions of $s m G F P$ to the CaLRRI and CaHIRI genes. To identify the CaHIR1 domains involved in punctate localization in the PM, truncated forms of CaHIRl were also cloned in p326GFP. Particle bombardment experiments were conducted as previously described (Choi et al. 2007).

\section{BiFC.}

BiFC experiments were conducted as previously described by Walter and associates (2004). The coding regions of the 
CaLRRI and CaHIRl genes were cloned into pSPYNE-35S and pSPYCE-35S. Agrobacterium tumefaciens GV3101 carrying each construct was infiltrated into the abaxial side of pepper leaves $\left(\mathrm{OD}_{600}=0.5\right.$ for each construct $)$. The epidermal cell layers of pepper leaves were observed by confocal laser scanning microscopy (LSM 5 Exciter) 1 and 2 days after infiltration.

\section{Agrobacterium-mediated transient expression assay.}

The agroexpression assay was performed as previously described (Choi et al. 2009; Jung and Hwang 2007). The coding regions of CaHIRl, CaLRR1, Pto, AvrPto, and Bax were cloned between the CaMV35 promoter and the nos terminator region in the binary vector pBIN35S. A. tumefaciens GV3101 containing each construct was grown overnight at $28^{\circ} \mathrm{C}$ in $\mathrm{LB}$ broth containing $50 \mu \mathrm{g}$ of kanamycin per milliliter and $100 \mu \mathrm{g}$ of rifampicin per milliliter. Bacterial cells were collected by centrifugation and were suspended in infiltration buffer $(10$ $\mathrm{mM} \mathrm{MgCl}_{2}, 10 \mathrm{mM}$ morpholineethanesulfonic acid, $\mathrm{pH} 5.7$, $200 \mu \mathrm{M}$ acetosyringone) to a final $\mathrm{OD}_{600}$ of 0.2 . Coexpression experiments were performed by mixing the Agrobacterium suspensions at a 1:1 ratio (final $\mathrm{OD}_{600}=0.2$ for each construct).

\section{VIGS.}

The TRV-based VIGS system was used for gene silencing in pepper and $N$. benthamiana (Liu et al. 2002). The full-length coding regions of CaLRRI and CaHIRl were amplified by PCR and were cloned into the vector pTRV2 to yield pTRV2: CaLRR1 and pTRV2:CaHIR1. A. tumefaciens GV3101 strains carrying pTRV1 or pTRV2 constructs were coinfiltrated into the fully expanded cotyledons of pepper and first leaves of $N$. benthamiana plants (final $\mathrm{OD}_{600}=0.2$ for each construct). Plants were placed in a growth room at $25^{\circ} \mathrm{C}$ with a 16 -h-light and 8-h-dark photoperiod cycle to allow growth and viral spread. Plants silenced for 4 to 5 weeks were used for pathogen inoculation.

\section{Histochemistry.}

Diaminobenzidine and trypan blue staining was performed as previously described (Choi et al. 2007). Aniline blue staining was performed to detect callose deposition as described by Adam and Somerville (1996). Pepper leaves were completely cleared in $20 \mathrm{ml}$ of alcoholic lactophenol (1 $\mathrm{ml}$ of lactic acid, 1 $\mathrm{ml}$ of glycerol, $1 \mathrm{~g}$ of phenol, and $1 \mathrm{ml}$ of $\mathrm{H}_{2} \mathrm{O}$ ), were rinsed in $50 \%$ ethanol and water, and were then stained for $30 \mathrm{~min}$ in $150 \mathrm{mM} \mathrm{K} \mathrm{HPO}_{4}(\mathrm{pH}$ 9.5) containing $0.05 \%$ aniline blue. Samples were mounted in $25 \%$ glycerol and were observed with a microscope equipped with a UV lamp (Olympus, Tokyo).

\section{Ion leakage measurement.}

Six leaf disks of defined area $(0.6 \mathrm{~cm}$ in diameter $)$ were removed and washed three times with distilled water following infiltration and were incubated in $3 \mathrm{ml}$ of distilled water at room temperature. The conductivity of the incubation medium was recorded at various timepoints with a conductivity meter.

\section{Determination of SA.}

SA was measured as previously described (Aboul-Soud et al. 2004). Pepper leaf tissues ( $1 \mathrm{~g}$ ) were homogenized in liquid nitrogen and were extracted with $1 \mathrm{ml}$ of $90 \%$ methanol and were then disrupted by sonication for $15 \mathrm{~min}$. After centrifugation, the pellet was re-extracted with $1 \mathrm{ml}$ of absolute methanol. As an internal standard for SA recovery, $20 \mu \mathrm{g}$ of 3hydroxy benzoic acid was added to the samples. The combined supernatants were dried in a speed vacuum. The residue was resuspended in $1 \mathrm{ml}$ of $5 \%$ trichloroacetic acid and was sonicated for $10 \mathrm{~min}$. Organic extraction of free SA was performed by adding $1 \mathrm{ml}$ of ethylacetate/cyclopentane/isopropanol
(50:50:1). After two-phase separation, the aqueous phase that contained the conjugated SA was acidified with $\mathrm{HCl}$ to $\mathrm{pH} 1$ and boiled for $30 \mathrm{~min}$ and, then, was extracted with the organic mixture to release free SA from acid-labile conjugated forms. The organic phase containing free SA was transferred to a 2$\mathrm{ml}$ tube and dried under nitrogen gas. The dried extract was suspended in $0.5 \mathrm{ml}$ of high-pressure liquid chromatography (HPLC) mobile phase (55\% acetonitrile [ACN], $45 \% \mathrm{dH}_{2} \mathrm{O}$ with $4 \%$ [vol/vol] acetic acid) and was filtered and analyzed by HPLC (Waters, Milford, MA, U.S.A.) equipped with a $\mathrm{C}_{18}$ analytical column (J'sphere ODS-H80, $150 \times 4.6 \mathrm{~mm}$ ) (YMC, Kyoto, Japan) and fluorescence detector (excitation $305 \mathrm{~nm}$ and emission $405 \mathrm{~nm}$ ) (Waters). The HPLC was programmed for gradient elution $\left(55 \% \mathrm{ACN}, 45 \% \mathrm{dH}_{2} \mathrm{O}\right.$ with $4 \%$ [vol $\left./ \mathrm{vol}\right]$ acetic acid to $80 \% \mathrm{ACN}, 20 \% \mathrm{dH}_{2} \mathrm{O}$ with $4 \%$ acetic acid [vol/vol] over $10 \mathrm{~min}$ ) at a flow rate of $1.0 \mathrm{ml} \mathrm{min}^{-1}$. SA and glucoside-conjugated SA levels were quantified by area integration of the HPLC peaks.

\section{Statistical analysis.}

Data for each experiment were analyzed using the SAS 8.2 statistical package (SAS Institute, Cary NC, U.S.A.]). Analysis of variance was carried out using the SAS general linear modeling procedure. Means were compared using Fisher's least significant difference tests, and different characters in the figures indicate significant differences.

\section{ACKNOWLEDGMENTS}

This work was supported by a grant (CG1133) from the Crop Functional Genomics Center of the 21st Century, Frontier Research Program funded by the Ministry of Education, Science and Technology, Korea, a grant (2010-0007194) from the Basic Science Research Program, the National Research Foundation of Korea (NRF) funded by the Ministry of Education, Science and Technology, Korea and a grant (K0715341) from Korea University, Korea. We thank S. P. Dinesh-Kumar (Yale University) for the pTRV1 and pTRV2 vectors and U. Bonas (Martin-Luther-Universität) for Agrobacterium tumefaciens GV3101.

\section{LITERATURE CITED}

Aboul-Soud, M. A. M., Cook, K., and Loake, G. J. 2004. Measurement of salicylic acid by a high-performance liquid chromatography procedure based on ion-exchange. Chromatographia 59:129-133.

Adam, L., and Somerville, S. C. 1996. Genetic characterization of five powdery mildew disease resistance loci in Arabidopsis thaliana. Plant J. 9:341-356.

Ahn, C. S., Lee, J. H., Hwang, A. R., Kim, W. T., and Pai, H. S. 2006. Prohibitin is involved in mitochondrial biogenesis in plants. Plant J. 46:658-667.

Babuke, T., and Tikkanen, R. 2007. Dissecting the molecular function of reggie/flotillin proteins. Eur. J. Cell Biol. 86:525-532.

Balagué, C., Lin, B., Alcon, C., Flottes, G., Malmström, S., Köhler, C., Neuhaus, G., Pelletier, G., Gaymard, F., and Roby, D. 2003. HLM1, an essential signaling component in the hypersensitive response, is a member of the cyclic nucleotide-gated channel ion channel family. Plant Cell 15:365-379.

Banerjee, D., Zhan, X., and Bent, A. F. 2001. The leucine-rich repeat domain can determine effective interaction between RPS2 and other host factors in Arabidopsis RPS2-mediated disease resistance. Genetics 158:439-450.

Bradford, M. M. 1976. A rapid and sensitive method for the quantitation of microgram quantities of protein utilizing the principle of protein-dye binding. Anal. Biochem. 72:248-254.

Browman, D. T., Hoegg, M. B., and Robbins, S. M. 2007. The SPFH domain-containing proteins: More than lipid raft markers. Trends Cell Biol. 17:394-402.

Chen, F., Yuan, Y., Li, Q., and He, Z. 2007. Proteomic analysis of rice plasma membrane reveals proteins involved in early defense response to bacterial blight. Proteomics 7:1529-1539.

Choi, H. W., Kim, Y. J., Lee, S. C., Hong, J. K., and Hwang, B. K. 2007. Hydrogen peroxide generation by the pepper extracellular peroxidase $\mathrm{CaPO} 2$ activates local and systemic cell death and defense response to 
bacterial pathogens. Plant Physiol. 145:890-904.

Choi, H. W., Lee, B. G., Kim, N. H., Park, Y., Lim, C. W., Song, H. K., and Hwang, B. K. 2008. A role for a menthone reductase in resistance against microbial pathogens in plants. Plant Physiol. 148:383-401.

Choi, H. W., Lee, D. H., and Hwang, B. K. 2009. The pepper calmodulin gene $\mathrm{CaCaM1}$ is involved in reactive oxygen species and nitric oxide generation required for cell death and the defense response. Mol. PlantMicrobe Interact. 22:1389-1400.

Chung, E., Oh, S. K., Park, J. M., and Choi, D. 2007. Expression and promoter analyses of pepper CaCDPK4 (Capsicum annuum calcium dependent protein kinase 4) during plant defense response to incompatible pathogen. Plant Pathol. J. 23:76-89.

Clough, S. J., Fengler, K. A., Yu, I. C., Lippok, B., Smith, R. K. Jr., and Bent, A. F. 2000. The Arabidopsis dndl "defense, no death" gene encodes a mutated cyclic nucleotide-gated ion channel. Proc. Natl. Acad. Sci. U.S.A. 97:9323-9328.

del Pozo, O., Pedley, K. F., and Martin, G. B. 2004. MAPKKK $\alpha$ is a positive regulator of cell death associated with both plant immunity and disease. EMBO (Eur. Mol. Biol. Organ.) J. 23:3072-3082.

Devadas, S. K., and Raina, R. 2002. Preexisting systemic acquired resistance suppresses hypersensitive response-associated cell death in Arabidopsis hrll mutant. Plant Physiol. 128:1234-1244.

Do, H. M., Hong, J. K., Jung, H. W., Kim, S. H., Ham, J. H., and Hwang, B. K. 2003. Expression of peroxidase-like genes, $\mathrm{H}_{2} \mathrm{O}_{2}$ production, and peroxidase activity during the hypersensitive response to Xanthomonas campestris pv. vesicatoria in Capsicum annuиm. Mol. Plant-Microbe Interact. 16:196-205.

Durrant, W. E., and Dong, X. 2001. Systemic acquired resistance. Annu. Rev. Phytopathol. 42:185-209.

Federici, L., Di Matteo, A., Fernandez-Recio, J., Tsernoglou, D., and Cervone, F. 2006. Polygalacturonase inhibiting proteins: Players in plant innate immunity? Trends Plant Sci. 11:65-70.

Greenberg, J. T., and Yao, N. 2004. The role and regulation of programmed cell death in plant-pathogen interactions. Cell Microbiol. 6:201-211.

Greenberg, J. T., Silverman, F. P., and Liang, H. 2000. Uncoupling salicylic acid-dependent cell death and defense-related responses from disease resistance in the Arabidopsis mutant acd5. Genetics 156:341-350.

Hwang, S. Kim, J., Kim, Y. H., and Kim, H. T. 2008. ABA increases susceptibility of pepper fruits to infection of anthracnose by Collectotrichum acutatum. Plant Pathol. J. 24:400-406.

Jacques, A., Ghannam, A., Erhardt, M., de Ruffray, P., Baillieul, F., and Kauffmann, S. 2006. NtLRP1, a tobacco leucine-rich repeat gene with a possible role as a modulator of the hypersensitive response. Mol. PlantMicrobe Interact. 19:747-757.

Jones, J. D., and Dangl, J. L. 2006. The plant immune system. Nature 444:323-329

Jung, H. W., and Hwang, B. K. 2007. The leucine-rich repeat (LRR) protein, CaLRR1, interacts with the hypersensitive induced reaction (HIR) protein, CaHIR1, and suppresses cell death induced by CaHIR1 protein. Mol. Plant Pathol. 8:503-514.

Jung, H. W., Lim, C. W., Lee, S. C., Choi, H. W., Hwang, C. H., and Hwang, B. K. 2008. Distinct roles of the pepper hypersensitive induced reaction protein gene CaHIRl in disease and osmotic stress, as determined by comparative transcriptome and proteome analyses. Planta 227:409-425

Jung, E. H., Jung, H. W., Lee, S. C., Han, S. W., Heu, S., and Hwang, B. K. 2004. Identification of a novel pathogen-induced gene encoding a leucinerich repeat protein expressed in phloem cells of Capsicum annuиm. Biochim. Biophys. Acta. 1676:211-222.

Karrer, E. E., Beachy, R. N., and Holt, C. A. 1998. Cloning of tobacco genes that elicit the hypersensitive response. Plant Mol. Biol. 36:681690

Kim, B. S., Kim, Y. C., Shin, K. S., and Kim, J. H. 2007 Near-isogenic lines for genes conferring hypersensitive resistance to bacterial spot in chili pepper. Plant Pathol. J. 23:155-160.

Kobe, B., and Kajava, A. V. 2001. The leucine-rich repeat as a protein recognition motif. Curr. Opin. Struct. Biol. 11:725-732.

Lacomme, C., and Santa Cruz, S. 1999. Bax-induced cell death in tobacco is similar to the hypersensitive response. Proc. Natl. Acad. Sci. U.S.A. 96:7956-7961.

Langhorst, M. F., Reuter, A., Jaeger, F. A., Wippich, F. M., Luxenhofer, G., Plattner, H., and Stuermer, C. A. 2008. Reggies/flotillins regulate cytoskeletal remodeling during neuronal differentiation via CAP/ponsin and Rho GTPases. Eur. J. Cell Biol. 87:921-931.

Langhorst, M. F., Solis, G. P., Hannbeck, S., Plattner, H., and Stuermer, C. A. 2007. Linking membrane microdomains to the cytoskeleton: Regula- tion of the lateral mobility of reggie-1/flotillin-2 by interaction with actin. FEBS (Fed. Eur. Biochem. Soc.) Lett. 581:4697-4703.

Latif, R., Ando, T., Daniel, S., and Davies, T.F. 2003. Localization and regulation of thyrotropin receptors within lipid rafts. Endocrinology 144:4725-4728.

Lee, S. C., Hwang, I. S., Choi, H. W., and Hwang, B. K. 2008. Involvement of the pepper antimicrobial protein $C a A M P 1$ gene in broad spectrum disease resistance. Plant Physiol. 148:1004-1020.

Liu, Y., Schiff, M., and Dinesh-Kumar, S. P. 2002. Virus-induced gene silencing in tomato. Plant J. 31:777-786.

Mühlenbock, P., Szechynska-Hebda, M., Plaszczyca, M., Baudo, M., Mateo, A., Mullineaux, P. M., Parker, J. E., Karpinska, B., and Karpinski, S. 2008. Chloroplast signaling and LESION SIMULATING DISEASE1 regulate crosstalk between light acclimation and immunity in Arabidopsis. Plant Cell 20:2339-2356.

Nadimpalli, R., Yalpani, N., Johal, G. S., and Simmons, C. R. 2000. Prohibitins, stomatins, and plant disease response genes compose a protein superfamily that controls cell proliferation, ion channel regulation, and death. J. Biol. Chem. 275:29579-29586.

Navarre, D. A., and Wolpert, T. J. 1999. Victorin induction of an apoptotic/senescence-like response in oats. Plant Cell 11:237-249.

Nishimura, M. T., Stein, M., Hou, B. H., Vogel, J. P., Edwards, H., and Somerville, S. C. 2003. Loss of a callose synthase results in salicylic acid-dependent disease resistance. Science 301:969-972.

Padmanabhan, M., Cournoyer, P., and Dinesh-Kumar, S. P. 2009. The leucine-rich repeat domain in plant innate immunity: A wealth of possibilities. Cell Microbiol. 11:191-198.

Park, J. M. 2005. The hypersensitive response. A cell death during disease resistance. Plant Pathol. J. 21:99-101

Reape, T. J., and McCabe, P. F. 2008. Apoptotic-like programmed cell death in plants. New Phytol. 180:13-26.

Rivera-Milla, E., Stuermer, C. A., and Málaga-Trillo, E. 2006. Ancient origin of reggie (flotillin), reggie-like, and other lipid-raft proteins: Convergent evolution of the SPFH domain. Cell Mol. Life Sci. 63:343-357.

Rostoks, N., Schmierer, D., Kudrna, D., and Kleinhofs, A. 2003. Barley putative hypersensitive induced reaction genes: Genetic mapping, sequence analyses and differential expression in disease lesion mimic mutants. Theor. Appl. Genet. 107:1094-1101.

Sessa, G., D'Ascenzo, M., and Martin, G. B. 2000. Thr38 and Ser198 are Pto autophosphorylation sites required for the AvrPto-Pto-mediated hypersensitive response. EMBO (Eur. Mol. Biol. Organ.) J. 19:2257-2269.

Shanmugam, V. 2005. Role of extracytoplasmic leucine-rich repeat proteins in plant defence mechanisms. Microbiol. Res. 160:83-94.

Solis, G. P., Hoegg, M., Munderloh, C., Schrock, Y., Malaga-Trillo, E., Rivera-Milla, E., and Stuermer, C. A. 2007. Reggie/flotillin proteins are organized into stable tetramers in membrane microdomains. Biochem. J. 403:313-322

Vlot, A. C., Dempsey, D. A., and Klessig, D. F. 2009. Salicylic Acid, a multifaceted hormone to combat disease. Annu. Rev. Phytopathol. 47:177-206.

Walter, M., Chaban, C., Schütze, K., Batistic, O., Weckermann, K., Näke, C., Blazevic, D., Grefen, C., Schumacher, K., Oecking, C., Harter, K. and Kudla, J. 2004. Visualization of protein interactions in living plant cells using bimolecular fluorescence complementation. Plant J. 40:428 438.

Williams, B., and Dickman, M. 2008. Plant programmed cell death: Can't live with it; can't live without it. Mol. Plant Pathol. 9:531-544.

Yao, N., and Greenberg, J. T. 2006. Arabidopsis ACCELERATED CELL DEATH2 modulates programmed cell death. Plant Cell 18:397-411.

Yao, N., Imai, S., Tada, Y., Nakayashiki, H., Tosa, Y., Park, P., and Mayama, S. 2002. Apoptotic cell death is a common response to pathogen attack in oats. Mol. Plant-Microbe Interact. 15:1000-1007.

Yu, I. C., Parker, J., and Bent, A. F. 1998. Gene-for-gene disease resistance without the hypersensitive response in Arabidopsis $d n d 1$ mutant. Proc. Natl. Acad. Sci. U.S.A. 95:7819-7824.

Zhou, L., Cheung, M. Y., Zhang, Q., Lei, C. L., Zhang, S. H., Sun, S. S., and Lam, H. M. 2009. A novel simple extracellular leucine-rich repeat (eLRR) domain protein from rice (OsLRR1) enters the endosomal pathway and interacts with the hypersensitive-induced reaction protein 1 (OsHIR1). Plant Cell Environ. 32:1804-1820.

\section{AUTHOR-RECOMMENDED INTERNET RESOURCES}

SMART database: smart.embl-heidelberg.de

TMpred database: www.ch.embnet.org/software/ TMPRED_form.html 